\title{
THE GENETICAL ANALYSIS OF AN INDUCED HEIGHT MUTANT IN WHEAT
}

\author{
A. J. WORLAND, C. N. LAW and A. SHAKOOR* \\ Plant Breeding Institute, Cambridge, England
}

Received 4.ii.80

\begin{abstract}
SUMMARY
Three semi-dwarf mutants were isolated after treating monosomics of homoeologous group 2 of the tall wheat "Bersée" with ethyl methanesulphonate (EMS). Two of the mutant lines were shown to have a single identical mutated gene, designated $R h t 7$, on chromosome $2 \mathrm{~A}$. Little evidence could be found for chromosomes hemizygous at the time of treatment with mutagens having an increased sensitivity to mutation. Lines carrying $R h t 7$ were shown to have reduced yields so that this mutation will probably be of little use in the breeding of high yielding short-strawed wheats.
\end{abstract}

\section{INTRODUCTION}

IN bread wheat, Triticum aestivum $(2 n=6 x=42)$, it has been suggested by Tsunewaki and Heyne (1959) that the chances of detecting a recessive mutant could be increased by treating monosomic rather than euploid seeds. Many recessive genes would be expressed on a hemizygous chromosome but would be masked if a non-mutated homologous chromosome was present. Chromosomes in the hemizygous condition also appear to be more sensitive to mutagens.

If this approach of mutating monosomics is to be used, it should be possible to further increase the chances of mutating genes for a certain character by treating monosomics known to carry genes for the character in question. For final plant height each of the chromosomes of homoeologous group 2 were shown to have marked effects since monosomes of this group in the variety Bersée were uniformly dwarfed (Law and Worland, 1973). This height reduction, amounting to 40 per cent of euploid, is probably due to reduced gibberellic acid synthesis (Gale and Law, 1973). Accordingly, an attempt was made to produce a semi-dwarf mutant in Bersée following treatment of the group 2 monosomics of this variety with the chemical mutagen, ethyl methanesulphonate (EMS). This mutagen is considered to be one of the most effective for wheat (Shama Rao and Sears, 1962; Konzak et al., 1969).

By treating seeds of group 2 Bersée monosomics with EMS, three semi-dwarf mutants were produced (Chaudhry, 1973). This paper describes attempts to establish whether these mutations occurred in the group 2 chromosomes.

Since the successful introduction of semi-dwarfing genes from the variety Norin 10-Brevor 14, large advances have been made in increasing the yield of wheat. This is partly because short strawed wheats allow further increases of yield to be obtained by their ability to utilise higher levels of artificial fertilisers without lodging. However, in most wheat crosses an increase in

* Present address: Nuclear Institute for Agriculture and Biology, P.O. Box 128, Lyallpur, Pakistan. 
yield is genetically correlated with an increased height (Law et al., 1978) so that the development of short-strawed wheats per se is not necessarily the way to higher yields. The particular advantages of the semi-dwarfing genes, $R h t 1$ and $R h t 2$, from Norin 10 (and the reason for their successful exploitation in breeding) is that they reduce height without a correlated yield reduction (Gale and Law, 1977; Gale, 1980). This paper therefore also describes experiments to determine the consequences of the Bersée height mutants on plant yield and other characters of agronomic interest to see whether they might be of similar use in breeding programmes.

\section{THE MUTANTS}

The semi-dwarf mutants were obtained by A. Shakoor (Chaudhry, 1973) from the treatment of dry seeds of each of the group 2 Bersée monosomics with a 0.5 per cent EMS solution for 17 hours. Forty per cent of the treated seeds survived to maturity and of these 169 or 38 per cent were selected from the $M_{1}$ generation as being of short stature. The majority of these plants would be non-mutated monosomics but a few would be monosomic mutants. The only disomic plants selected would be ones carrying dominant mutations for dwarfism.

All ears of selected $M_{1}$ plants were selfed and 2814 seedlings were grown under glasshouse conditions as the $M_{2}$ generation. Of these, 380 were selected for reduced height and selfed to provide grain for an $\mathbf{M}_{3}$ field trial.

In the $\mathrm{M}_{3}$ generation, progenies of each of 380 lines were scored for uniformity of height reduction. Only two families were found to be uniformly short and to be disomic. These lines are referred to as mutants A and B. A third line segregated for height in the $\mathrm{M}_{3}$ trial giving a number of very short plants of which one was disomic. Grown on for an $\mathrm{M}_{4}$ generation this progeny yielded the uniformly short line, mutant $C$.

(i) Mutant A. (13-818-10). This mutant was derived from Bersée monosomic 2B. Plants grown in pots under glasshouse conditions are $77 \mathrm{~cm}$ high, 37 per cent shorter than Bersée. The height reduction is achieved by proportionate reductions of all internodes with a major part being through reductions of the first and second internodes. The spike is awnless and is 3.4 per cent shorter than Bersée. The stem appears to be stronger and stiffer than Bersée. Coleoptile length is reduced.

(ii) Mutant B. (13-685-5). This mutant was also derived from Bersée $2 B$. In the glasshouse, plants were $86 \mathrm{~cm}$ high, a reduction of 30 per cent on Bersée. The height reduction is due to proportionate reductions in all internodes. Spikes are awned and 9.4 per cent shorter than Bersée and the coleoptile length is reduced.

(iii) Mutant C. (13-1047-3-1). This mutant was also derived from Bersée 2B. It is the shortest of the three mutants at $72 \mathrm{~cm}$. This represents a 41 per cent reduction on Bersée. All internodes are reduced proportionately. Spikes are awned, and are $9.4 \mathrm{~cm}$ long, a 27 per cent reduction on Bersée. Coleoptile length is reduced.

\section{Methods}

(i) The chromosomal location of mutant loci

Although all the mutant lines were obtained from among the progeny of Bersée monosomic 2B, each of the lines was crossed as pollen parent to each 
of the group 2 Bersée monosomics, 2A, 2B and 2D. From these crosses, $F_{1}$ monosomic plants were selected by scoring root tip cells stained in Feulgen.

These monosomic hybrids carry, depending upon the monosomic status of the maternal parent, either chromosome $2 \mathrm{~A}, 2 \mathrm{~B}$ or $2 \mathrm{D}$ from the mutant line in the hemizygous condition. The plants were grown in an unheated glasshouse during the summer of 1974 and selfed to obtain $F_{2}$ seed.

In the $F_{2}$ generation, separate experiments were carried out in 1975 for each of the three mutant lines. Each experiment included plants of Bersée and the mutant line. Seedlings were transplanted into the soil of a large glasshouse under automatic trickle irrigation. For each line, varying numbers of $F_{2}$ seedlings and their parents were grown in rows $15 \mathrm{~cm}$ on either side of irrigation tubes which were placed $90 \mathrm{~cm}$ apart. Within rows, plants were randomised and set at $25 \mathrm{~cm}$ intervals. Final plant heights were obtained from each plant at maturity.

The $F_{2}$ plants will segregate for the monosomic-disomic condition. This segregation can be distinguished easily because the monosomics of all the group 2 chromosomes have a characteristic ear type, flag leaf appearance, stem thickness as well as a reduced height which is not masked by the presence of the mutation(s) for height. The disomics of this generation will be homozygous for a particular group 2 chromosome of the mutant line involved in the initial hybridisation. Thus, if the mutant gene or genes for height are carried by this chromosome then all the selected disomics will be short, whereas if the mutant gene or genes are located on another chromosome or chromosomes, the disomics will not be uniformly short but will segregate. By examining the phenotypes of the various disomics it should therefore be possible to establish whether one or other of the group 2 chromosomes carry mutant alleles affecting height.

\section{(ii) Allelism and the effect of the height mutants on plant performance}

Intercrossing the three mutant lines followed by the study of the resulting $\mathrm{F}_{2}$ generation should provide a test for the presence or absence of allelism between the mutant alleles in the three lines. Experiments were therefore carried out to establish these relationships. These followed the chromosomal location experiments which, besides implicating one of the group 2 chromosomes as having a major effect on the control of height in certain of the mutant lines, indicated the presence of mutant alleles for height on chromomes other than group 2. As a consequence, attempts to remove the effect of these background mutations were made by backcrossing some of the mutant lines to the critical group 2 monosome of Bersée. Tests for allelism were made using some of the derivatives of this backcross programme.

Backcrossed derivatives of all three mutant lines were intercrossed and their $F_{1}$ hybrids grown and selfed under glasshouse conditions. The number of seeds obtained was sufficient to sow a randomised block experiment in the autumn of 1977. The experiment included Bersée, the three original mutant lines, at least one line of each mutant backcrossed to the appropriate Bersée monosomic and at least one line of each of the three possible intercrosses between them. Six replications were grown in separate randomised blocks. Individual replicates consisted of a single row of eleven seeds spaced $10 \mathrm{~cm}$ apart. Individual rows were spaced $30 \mathrm{~cm}$ apart with sixty rows forming a bed. 
At harvest time plants were measured for height and plant number and yield per row obtained. Grain weight per plant, 50 grain weight, tiller number and grain number per ear were measured on individual plants from a single block.

\section{Results}

\section{(i) Chromosomal location}

(a) Mutant $A$. The mean heights of monosomic and disomic $F_{2}$ plants obtained from crossing this mutant to each of the group 2 monosomics along with the mean heights of Bersée and the mutant line are given in table 1 . The

TABLE 1

Mean final plant heights obtained in experiments involving each of the three mutant lines, Bersée and $F_{2}$ monosomic hybrid populations derived by crossing the mutant lines to each of the three group 2 monosomics of Bersée, grouped according to whether they were monosomic or disomic

Mutant A

\begin{tabular}{|c|c|c|c|}
\hline $\begin{array}{l}\text { No. of } \\
\text { plants }\end{array}$ & Monosomics & $\begin{array}{l}\text { No. of } \\
\text { plants }\end{array}$ & Disomics \\
\hline $\begin{array}{l}25 \\
18 \\
32\end{array}$ & $\begin{array}{l}78 \cdot 2 \pm 1 \cdot 02 \\
84 \cdot 6 \pm 1 \cdot 48 \\
88 \cdot 5 \pm 0.97\end{array}$ & $\begin{array}{l}24 \\
18 \\
24 \\
11 \\
21\end{array}$ & $\begin{array}{r}75 \cdot 7 \pm 1 \cdot 01 \\
117 \cdot 3 \pm 1 \cdot 52 \\
96 \cdot 1 \pm 0 \cdot 92 \\
106 \cdot 2 \pm 3 \cdot 31 \\
107 \cdot 9 \pm 2 \cdot 94\end{array}$ \\
\hline $\begin{array}{l}51 \\
77 \\
41\end{array}$ & $\begin{array}{l}79.69 \pm 0.83 \\
88.25 \pm 0.68 \\
89.46 \pm 0.67\end{array}$ & $\begin{array}{l}24 \\
18 \\
25 \\
40 \\
12\end{array}$ & $\begin{array}{r}97.67 \pm 0.84 \\
118.28 \pm 1.44 \\
110 \cdot 04 \pm 1.22 \\
110 \cdot 05 \pm 1.22 \\
109 \cdot 50 \pm 2.86\end{array}$ \\
\hline $\begin{array}{l}34 \\
41 \\
10\end{array}$ & $\begin{array}{c}\text { - } \\
\text { - } \\
74 \cdot 38 \pm 1 \cdot 25 \\
74 \cdot 88 \pm 2 \cdot 37 \\
74 \cdot 60 \pm 2 \cdot 45\end{array}$ & $\begin{array}{r}29 \\
54 \\
20 \\
15 \\
8\end{array}$ & $\begin{array}{r}72.97 \pm 0.76 \\
122.29 \pm 0.65 \\
87.45 \pm 1.86 \\
95.47 \pm 3.57 \\
99.25 \pm 4.34\end{array}$ \\
\hline
\end{tabular}

height distributions of the disomic progenies, Bersée and the mutant line are shown in fig. 1. At both the monosomic and disomic levels the mean of the monosomic $2 \mathrm{~A}$ cross was significantly shorter than the $2 \mathrm{~B}$ or $2 \mathrm{D}$ crosses which were not significantly different from each other. The height distributions show that for chrosome 2A all disomic progeny were significantly shorter than Bersée, pointing to a mutation(s) on this chromosome. With chromosomes $2 \mathrm{~B}$ and $2 \mathrm{D}$ in the disomic condition it was possible to select plants of a similar height to the tall parent, indicating that mutations had not taken place on these two chromosomes.

The heights of all three backcrossed mutant lines were significantly taller than the original mutant. This could be due to a number of additional smaller mutations on background chromosomes or a single larger mutation somewhere other than that established on chromosome $2 \mathrm{~A}$. The chromosome $2 \mathrm{~A}$ mutant(s) accounted for about 50 per cent of the reduction in height of mutant A compared with Bersée.

(b) Mutant $B$. The mean heights of the $F_{2}$ plants involving this mutant are also shown in table 1 and the appropriate plant height distributions in 

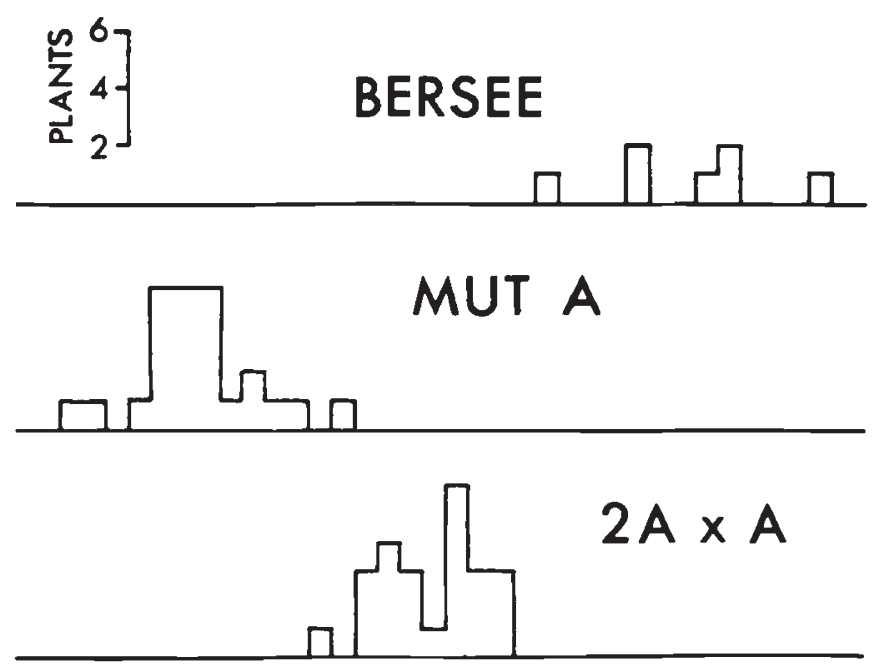

\section{$2 B \times A$}
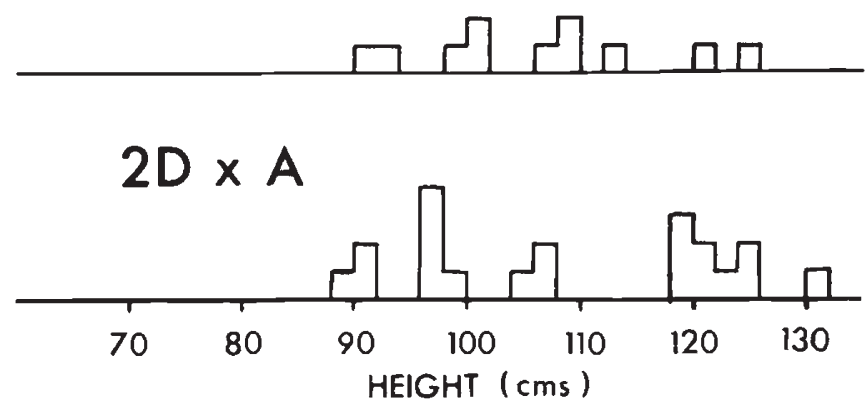

FIG. 1.-Final plant height distributions of Bersée and Mutant $A$ and disomics selected from the $F_{2}$ of Bersée monosomic $2 A \times$ Mutant $A(2 A \times A)$, the $F_{2}$ of Bersée monosomic $2 \mathrm{~B} \times$ Mutant $\mathrm{A}(2 \mathrm{~B} \times \mathrm{A})$ and the $\mathrm{F}_{2}$ of Bersée monosomic $2 \mathrm{D} \times$ Mutant $\mathrm{A}(2 \mathrm{D} \times \mathrm{A})$.

fig. 2. Again the monosomic progeny of the cross mutant B with Bersée 2A were significantly shorter than the monosomics of the other two chromosomes. The three disomic progenies, however, were indistinguishable. This could mean that the extra reduction in height among the monosomic progeny for chromosome $2 \mathrm{~A}$ was due to a condition of the monosomy itself. As all three disomic progenies segregated plants equal in height to the tall parent it can be concluded that none of these chromosomes has been mutated and suggests that the mutant allele(s) in this line is located on a chromosome(s) other than those belonging to homoeologous group 2.

(c) Mutant $C$. The mean heights and plant height distributions relating to this line are given in table 1 and fig. $3 . F_{2}$ monosomic progenies for the mutant crossed to each of the group 2 monosomics of Bersée are indistinguishable from each other. The disomic progeny for the cross involving 


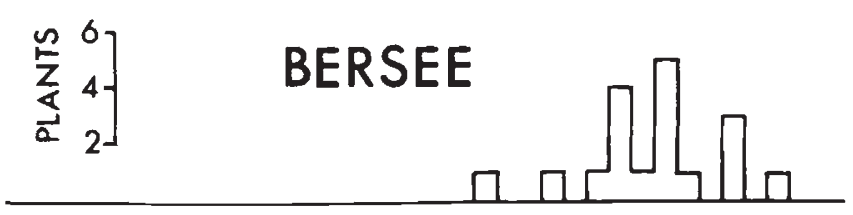

\section{MUT B}

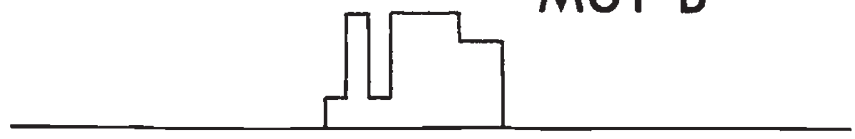

$2 A \times B$
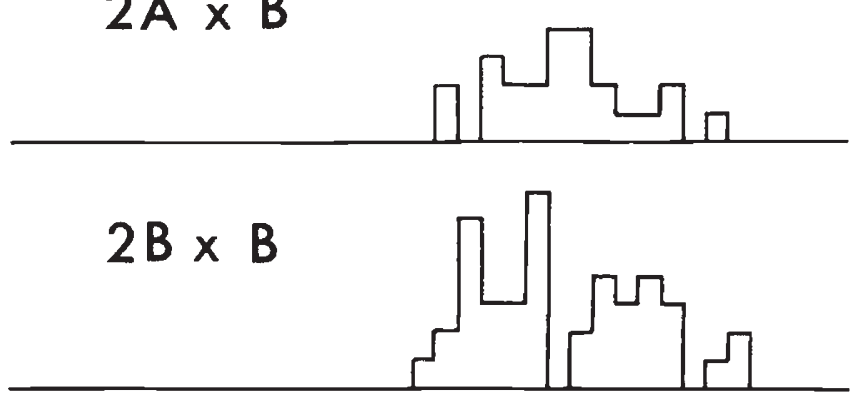

\section{$2 D \times B$}

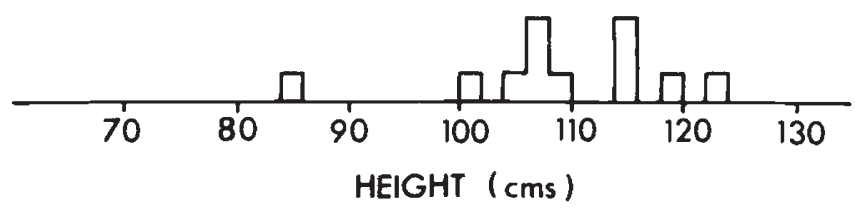

Fig. 2.-Final plant height distributions of Bersée and Mutant $B$ and disomics selected from the $F_{2}$ of Bersée monosomic $2 \mathrm{~A} \times$ Mutant $\mathrm{B}(2 \mathrm{~A} \times \mathrm{B})$, the $\mathrm{F}_{2}$ of Bersée monosomic $2 \mathrm{~B} \times$ Mutant $\mathrm{B}(2 \mathrm{~B} \times \mathrm{B})$ and the $\mathrm{F}_{2}$ of Bersée monosomic $2 \mathrm{D} \times$ Mutant $\mathrm{B}(2 \mathrm{D} \times \mathrm{B})$.

chromosome $2 \mathrm{~A}$ is, however, significantly shorter than crosses involving chromosomes 2B and 2D which are not significantly different from each other. Only in the progeny of the cross involving chromosome $2 \mathrm{~A}$ are all disomics much shorter than Bersée. Lines involving $2 \mathrm{~B}$ and $2 \mathrm{D}$ segregate plants equal in height to Bersée, suggesting that mutations have not occurred on these two chromosomes. The height reduction in the chromosome $2 \mathrm{~A}$ cross accounted for over 70 per cent of the reduction in height of mutant $\mathrm{C}$ compared with Bersée.

These three chromosomal location experiments were carried out separately but under similar conditions. A comparison of the two $2 \mathrm{~A}$ crosses where mutations have been shown to have occurred suggests that both cause similar reductions in height and could possibly be the same mutation. 

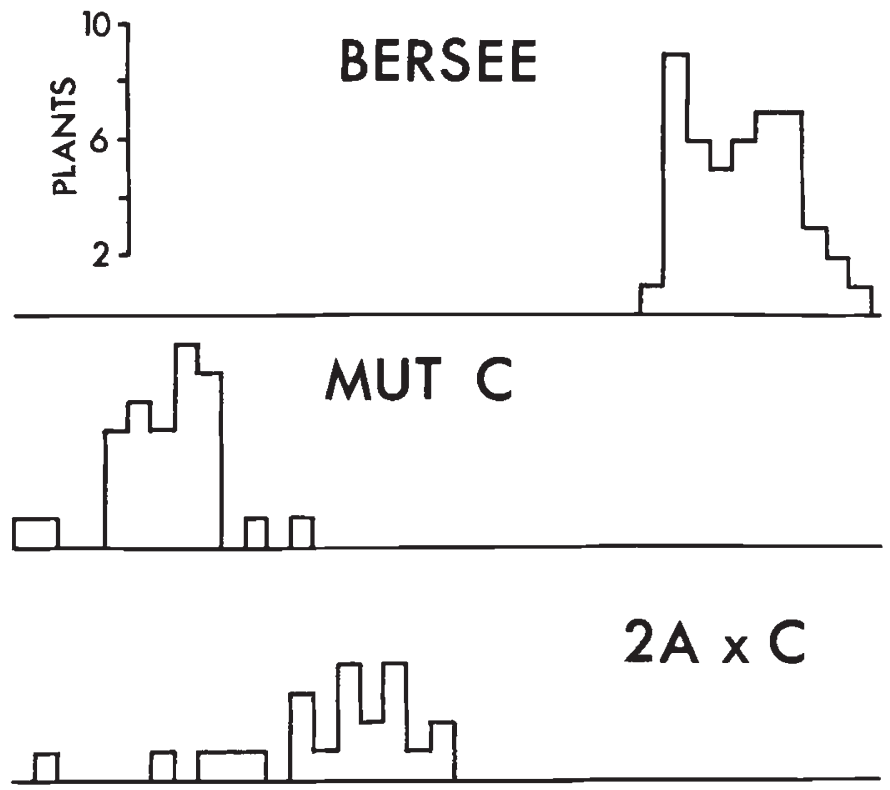

\section{$2 \mathrm{~B} \times \mathrm{C}$}
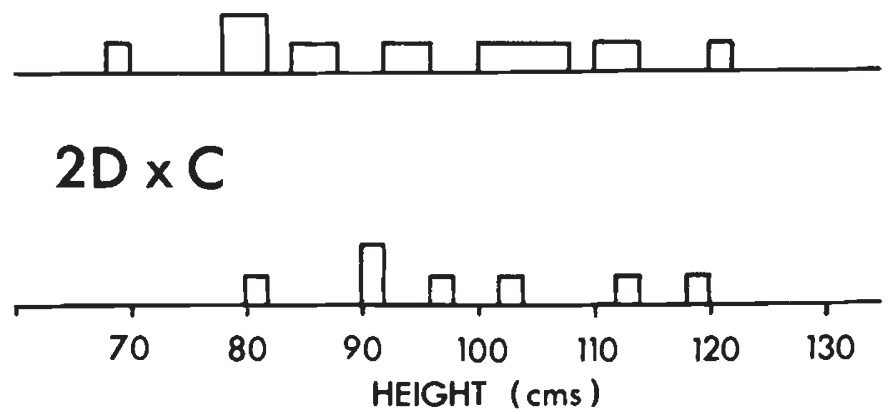

FrG. 3.-Final plant height distributions of Bersée and Mutant $\mathrm{C}$ and disomics selected from the $\mathrm{F}_{2}$ of Bersée monosomic $2 \mathrm{~A} \times$ Mutant $\mathrm{C}(2 \mathrm{~A} \times \mathrm{C})$, the $\mathrm{F}_{2}$ of Bersée monosomic $2 \mathrm{~B} \times$ Mutant $\mathrm{C}(2 \mathrm{~B} \times \mathrm{C})$ and the $\mathrm{F}_{2}$ of Bersée monosomic $2 \mathrm{D} \times$ Mutant $\mathrm{C}(2 \mathrm{D} \times \mathrm{C})$.

\section{(ii) Allelism}

The possibility that the mutations on chromosome $2 \mathrm{~A}$ in the mutant lines $A$ and $C$ are the same can be tested by intercrossing the lines and observing the resulting segregation. However, both these mutant lines carry allelic variation for height which is not located on chromosome $2 \mathrm{~A}$. This variation is likely therefore to complicate any test of allelism since it will obscure the segregation that may result from recombination of the $2 \mathrm{~A}$ homologues. For this reason, backcross derivatives of the mutant lines to Bersée monosomic $2 \mathrm{~A}$ were used in making the crosses to test for allelism.

In the case of mutant $\mathrm{A}$, a disomic line, Bersée 2A (Mutant $\mathrm{A}$ ), was selected by selfing the monosomic $F_{1}$ hybrid from the cross Bersée 
monosomic $2 \mathrm{~A}$ with mutant $\mathrm{A}$. For the mutant $\mathrm{C}$ line, two disomic lines of Bersée $2 \mathrm{~A}^{3}$ (Mutant $\mathrm{C}$ ) were obtained by selfing the monosomic hybrid produced after two backcrosses to Bersée monosomic 2A. Crosses were then made between Bersée 2A (Mutant A) and one of the Bersée $2 \mathrm{~A}^{3}$ (Mutant $\mathrm{C}$ ) lines. The $\mathrm{F}_{2}$ of three hybrids resulting from this cross, the original mutant $\mathrm{A}$ and $\mathrm{C}$ lines, Bersée and the backcross lines, Bersée 2A (Mutant A), Bersée $2 \mathrm{~A}^{3}$ (Mutant C) 1 and 2 were grown as described in section 3 and their means and distributions are given in fig. 4 .

The means of the backcross lines of Mutant $\mathrm{C}$ were significantly different, indicating that background variation was still present after two backcrosses to Bersée monosomic $2 \mathrm{~A}$. Likewise, the means of the three $\mathrm{F}_{2}$ crosses were significantly different from each other, suggesting again that background variation was responsible. However, none of the $F_{2}$ crosses showed transgressive segregation outside the limits of the backcross lines. Furthermore, none of the segregants was as tall as Bersée. This indicates
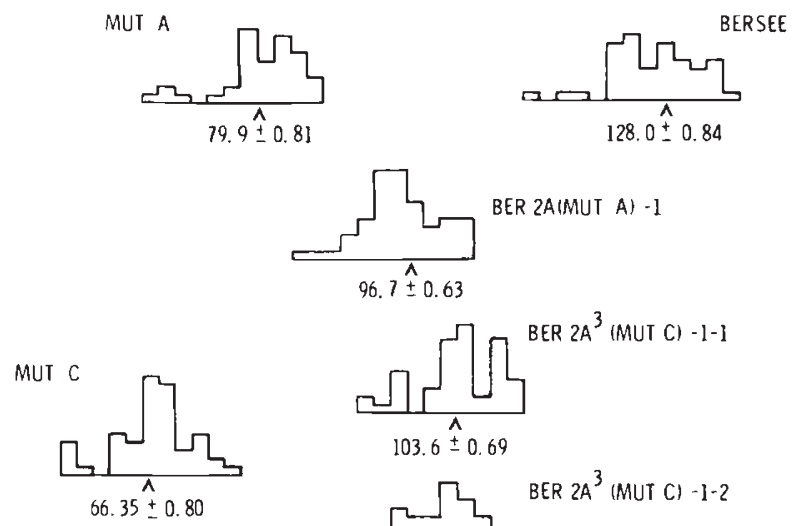

$103.6 \pm 0.69$
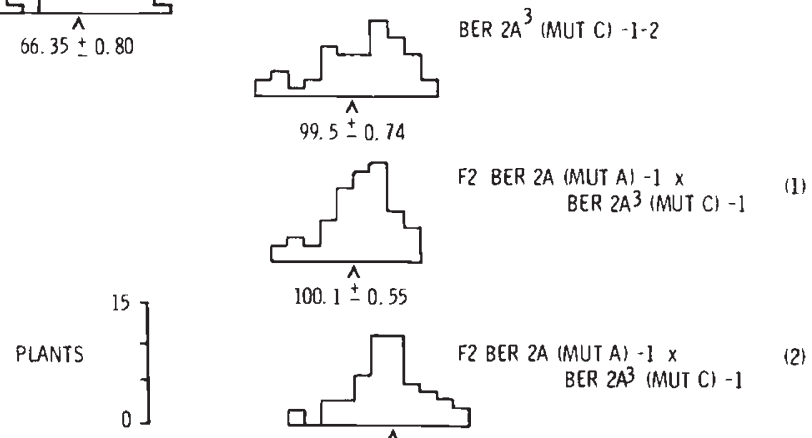

100. $1 \pm 0.55$

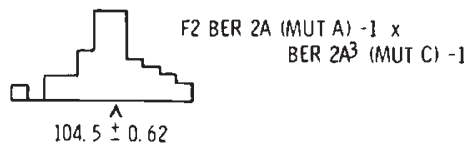

(2)

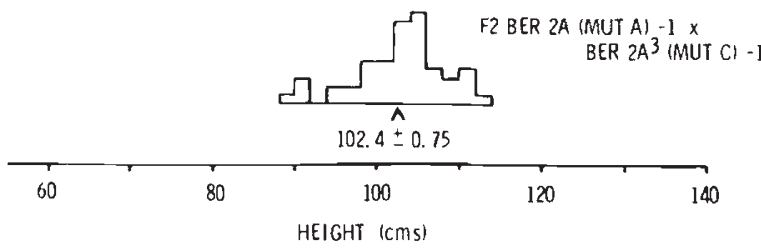

131

FIG. 4.-The means and distributions for final plant height of the Mutant A and C lines, Bersée, backcross derivatives of these two mutant lines to Bersée monosomic $2 \mathrm{~A}$, and three $\mathrm{F}_{2}$ populations resulting from intercrosses between them. 
that the variation associated with the induced mutation(s) on chromosome $2 \mathrm{~A}$ in these backcross mutant lines is not segregating and that identical alleles are found on both the $2 \mathrm{~A}$ homologues.

Since both the $\mathrm{A}$ and $\mathrm{C}$ mutant lines were derived independently, then it is unlikely that two or more identical mutations were induced at the same time in both lines. The more likely event is that a single but identical mutation affecting height has occurred in the two lines.

$\mathrm{F}_{2}$ families resulting from crosses between Bersée 2A (Mutant $\mathrm{A}$ ) and mutant $B$, and Bersée $2 A^{3}$ (Mutant $C$ ) and mutant $B$ were also grown in the experiment. In both cases, transgressive segregation was apparent and several segregants as tall as Bersée were observed. This confirms that the mutation(s) in line B is not located on chromosome $2 \mathrm{~A}$.

\section{(iii) The effect of the height mutation on yield and its components}

Plot yields and its components, 50 grain weight, tiller number and grain number per ear for each of the lines are given in table 2. The components of yield were obtained from plants harvested individually in the first replication, whereas the plot yields refer to the mean of six replications. Marked differences occur between the original mutant lines and their backcross derivatives and between all the lines and Bersée. The mean yields of Bersée 2A (Mutant A), Bersée $2 \mathrm{~A}^{3}$ (Mutant $\mathrm{C}$ ) and their $\mathrm{F}_{2}$ hybrids are approximately half that of Bersée. Similar reductions also occur for the yield components.

\section{TABLE 2}

Yields per plot and components of yield of Bersée, the original three mutant lines, the backcross derivatives of the $A$ and $C$ mutant lines and the $F_{2}$ of intercrosses between them. The results for Bersée $2 A^{3}$ (Mutant $C$ ) and $F_{2}$ Bersée $2 A$ (Mutant $\left.A\right) \times$ Bersée $2 A^{3}$ (Mutant $C$ ) are the means of two and three replicate lines respectively. The components of yield are based on single plant data from one replication only

\begin{tabular}{|c|c|c|c|c|}
\hline Line & $\begin{array}{l}\text { Mean plot } \\
\text { yields (gm) }\end{array}$ & $\begin{array}{c}50 \text { Grain } \\
\text { weight }(\mathrm{gm})\end{array}$ & $\begin{array}{c}\text { Tiller } \\
\text { number }\end{array}$ & $\begin{array}{l}\text { Grain number } \\
\text { per ear }\end{array}$ \\
\hline ant $A$ & $33.9 \pm 8 \cdot 6$ & $1 \cdot 29 \pm 0.03$ & $6 \cdot 6 \pm 0 \cdot 8$ & $25 \cdot 3 \pm 2 \cdot 5$ \\
\hline ant B & $93 \cdot 9 \pm 17 \cdot 8$ & $2.40 \pm 0.04$ & $10 \cdot 0 \pm 0 \cdot 5$ & $18 \cdot 1 \pm 1 \cdot 5$ \\
\hline nt $C$ & $7 \cdot 0 \pm 1 \cdot 7$ & $0.52 \pm 0.05$ & $2.75 \pm 0.6$ & $9 \cdot 4 \pm 0.91$ \\
\hline Mutant A) & $92 \cdot 9 \pm 8 \cdot 2$ & $1 \cdot 79 \pm 0 \cdot 10$ & $7 \cdot 75 \pm 0.6$ & $35 \cdot 5 \pm 2 \cdot 2$ \\
\hline (Mutant C) & $97 \cdot 5 \pm 7 \cdot 2$ & $1 \cdot 74 \pm 0 \cdot 04$ & $8.73 \pm 0.9$ & $43 \cdot 6 \pm 3 \cdot$ \\
\hline $2 A^{3}$ (Mutant C) & $\begin{array}{l}124 \cdot 7 \pm 6 \cdot 8 \\
241 \cdot 7 \pm 17 \cdot 2\end{array}$ & $\begin{array}{l}1.74 \pm 0.04 \\
2 \cdot 22 \pm 0.06\end{array}$ & $\begin{array}{l}8.57 \pm 0.6 \\
12 \cdot 7 \pm 1 \cdot 1\end{array}$ & $\begin{array}{l}42 \cdot 3 \pm 1 \cdot 4 \\
54 \cdot 9 \pm 2 \cdot 5\end{array}$ \\
\hline
\end{tabular}

There is also a strong positive correlation between height and yield $(r=0.98, P<0.001)$ as well as with 50 grain weight and grain number per ear $(r=0.80, P 0.01-0.001$ and $r=0.91, P<0.001$ respectively). This agrees with the correlation between height and yield observed by Law et al. (1978) among the derivatives of crosses between diverse wheat varieties.

\section{Discussion}

Of the three original semi-dwarf mutant lines, two, mutant $\mathrm{A}$ and $\mathrm{C}$, have been shown to carry a single, identical gene on chromosome $2 \mathrm{~A}$ which 
reduces the height of Bersée by about 30 per cent. The mutation(s) affecting height in the third line, mutant $B$, could not be located on any of the homoeologous group 2 chromosomes. In all three lines the results of the experiments indicated that a number of induced mutations, some having only minor effects on height, had been selected in the development of the mutant lines. These mutations also appeared not to be located on the group 2 chromosomes.

The major mutation on 2A was produced by EMS treatment of Bersee monosomic $2 \mathrm{~B}$ and not from its monosomic $2 \mathrm{~A}$ homoeologue. There thus appears to be little support for the suggestion of Tsunewaki and Heyne (1959) that mutations are more likely to occur, and be detected, on a chromosome hemizygous at the time of treatment. On the other hand, a decrease in chromosome dosage of a homoeologous group from six to five, as in monosomics might increase the chance of detecting and selecting height mutants on all the group 2 chromosomes. This could account for two of the mutational events, albeit at the same locus, being on a group 2 chromosome not hemizygous at the time of treatment.

The important semi-dwarfing genes, $R h t 1$ and $R h t 2$, from Norin 10 have been located on chromosomes 4A (Gale and Marshall, 1976) and 4D (Gale et al., 1975) respectively. A third gene, $R h t 3$, having a major effect on height and found in the variety Tom Thumb has been located on $4 \mathrm{~A}$, allelic to Rht 1 (Morris et al., 1972; Gale et al., 1975; Gale and Marshall, 1975). These three genes also have a pleiotropic effect on a plant's insensitivity to exogenous gibberellic acid (GA) (Gale, 1980). None of the mutant lines in this study were insensitive to GA so that, irrespective of chromosomal location, the mutation in lines $\mathrm{A}$ and $\mathrm{C}$ as well as those in line B are phenotypically different from $R h t 1, R h t 2$ and $R h t 3$. Three other semidwarf mutant genes, $R h t 4, R h t 5$ and $R h t 6$, have been isolated by Konzak (1976), and again none of these genes are insensitive to GA, so that it is possible that one of these genes could be allelic to the mutant on $2 \mathrm{~A}$. Since the chromosomal location of these genes is unknown, and since appropriate tests of allelism will take some time to complete, it is proposed that the gene on $2 \mathrm{~A}$ be given the provisional designation, $R h t 7$.

Successful semi-dwarf wheats occur among Mediterranean varieties, for example Mara (Italy) and Sava (Yugoslavia). These varieties are sensitive to GA so that neither $R h t 1, R h t 2$ nor $R h t 3$ are involved in the determination of their semi-dwarfism. A chromosome substitution series using Mara as donor and Cappelle-Desprez as recipient is being developed at this Institute and disomic substitutions after four backcrosses to the recipient have been selected. Field observations made on these lines indicate that a height reduction of about $15 \mathrm{~cm}$ occurs in duplicate substitution lines carrying chromosome 2D of Mara. This represents about 40 per cent of the height reduction of Mara compared with Cappelle-Desprez and implicates a group 2 chromosome in the control of semi-dwarfism in this important group of varieties. It is possible that this chromosomal effect may result from a similar allelic difference to $R h t 7$ on chromosome $2 \mathrm{~A}$.

In conclusion, the agronomic performance of the lines carrying $R h t 7$ was not encouraging. A positive relationship between height and yield and some of its components was observed. This would indicate that $R h t 7$ unlike $R h t 1$ and $R h t 2$ of Norin 10 would probably be of little use in breeding programmes seeking high yielding, short-strawed wheats. 


\section{REFERENCES}

CHAUDHRY, A. S. 1973. A genetic and cytogenetic study of height in wheat. Ph.D. thesis, Cambridge University.

GALE, M. D. 1980. The effects of Norin 10 dwarfing genes on yield. Proc. VInt. Wheat Genetic Symposium, New Delhi (1978) (in press).

GALE, M. D., AND LAW, C. N. 1973. Semi-dwarf wheats induced by monosomy and associated changes in gibberellin levels. Nature, 241, 211-212.

GALE, M. D., AND LAW, C. N. 1977. Norin 10-based semi-dwarfism. In Genetic Diversity in Plants. Plenum Press, New York, 133-151.

GALE, M. D., LAW, C. N., MARShALL, G. A., AND WORLAND, A. J. 1975. The genetic control of gibberellic acid insensitivity and coleoptile length in a "dwarf" wheat. Heredity, 34, 393-399.

GALE, M. D., LAW, C. N., AND WORLAND, A. J. 1975. The chromosomal location of a major dwarfing gene from Norin 10 in new British sem-dwarf wheats. Heredity, 35, 417-421.

GALE, M. D., AND MARSHALL, G. A. 1975. The nature and genetic control of gibberellin insensitivity in dwarf wheat grain. Heredity, 35, 55-65.

GALE, M. D., AND MARShALL, G. A. 1976. The chromosomal location of Gai1 and Rht1, genes for gibberellin insensitivity and semi-dwarfism, in a derivative of Norin 10 wheat. Heredity, 37, 283-289.

KONZAK, C. F., WOO, S. C., AND DICKEY, J. 1969. An induced dominant semi-dwarf plant height mutation in spring wheat. Wheat Information Service, No. $28,10$.

KONZAK, C. F. 1976. A review of semi-dwarfing gene sources and a description of some new mutants useful for breeding short-stature wheats. In Induced mutations in cross-breeding. IAEA, Vienna, 79-83.

LAW, C. N., AND WORLAND, A. J. 1973. Aneuploidy in wheat and its uses in genetic analysis. Plant Breeding Institute Annual Report, 1972, 26-65.

LAW, C. N., SNAPE, J. W., AND WORLAND, A. J. 1978. The genetic relationship between height and yield in wheat. Heredity, 40, 133-151.

MORRIS, R., SCHMIDT, J. W., AND JOHNSON, U. A. 1972. Chromosomal location of a dwarfing gene in Tom Thumb wheat derivatives by monosomic analysis. Crop Sci., 7, 275-276.

SHAMA RAO, H. K., AND SEARS, E. R. 1962. EMS induced mutations in hexaploid wheat. Genetics, 47, 983-984.

TSUNEWAKI, K., AND HEYNE, E. G. 1959. Radiological study of wheat monosomics. 1. Differential sensitivity of monosomic $\mathrm{X}$ and the disomic to $\mathrm{X}$-irradiation. Genetics, 44, 933-946. 